Open Access

\title{
Technologically-mediated communication: student expectations and experiences in a FOMO society
}

Angela T. Ragusa

Correspondence: aragusa@csu.edu.au

School Humanities and Social Sciences, Charles Sturt University, Albury, NSW, Australia

\begin{abstract}
While technology enables a wider section of society to access higher education, accessing, as a process, fundamentally differs from acquiring the individual and systemic skills required for online learning. This study presents primary data about perceptions of, and experiences with, online learning in an Australian university from a survey of 289 distance education (DE) students. Epistemologically, it prioritises giving agency and voice to an increasingly disempowered collective, online learners, who often are institutionally pursued for economic advantage, rather than pedagogical interest in serving students' unique, individual needs/preferences. Participants' comparison of face-to-face and online learning experiences allowed for benefits and disadvantages of online learning to emerge from lived-experiences. While a key benefit of online learning was its perceived 'flexibility', findings revealed difference between students' conceptualisation of flexibility and institutional realities. Although DE students longed for non-technologically-medicated communication with peers and lecturers, the process of learning how to become a DE student failed to address students' needs/ concerns beyond technical skill acquisition and subject content mastery. Students' 'fear they were missing out' (FOMO) on 'better' internal classroom and learning experiences was a key limitation $85 \%$ perceived about DE. Whereas traditional classroom experiences generally were recalled favourably, online learning was described by its shortcomings. Findings demonstrate need for deeper investigation of how/why educational technologies are implemented. Conclusions suggest critical research investigating whether embedded technologies meet student and/or institutional needs and aspirations in globally competitive learning environments may assuage DE's stigma, realign expectations and improve teaching/learning experiences.
\end{abstract}

Keywords: Distance education, Online learning, Computer-mediated communication, Learning preferences, Isolation

\section{Introduction and literature review}

Digital, computer-mediated communication (CMC), or technologically-mediated communication (TMC), is one of the most fundamental social changes characterising society's transition from modernity to post-modernity (García-Jiménez, 2012). TMC affects how we interact as our social order is refashioned from 'structural' to increasingly 'individualistic'. Alongside traditional demographic categories, 'social reality' is shaped by 'new' communication technologies that create more permeable, plastic, and fluid social boundaries facilitated by democratised, pluralised media appearing to support

(C) The Author(s). 2017 Open Access This article is distributed under the terms of the Creative Commons Attribution 4.0 International License (http://creativecommons.org/licenses/by/4.0/), which permits unrestricted use, distribution, and reproduction in any medium, provided you give appropriate credit to the original author(s) and the source, provide a link to the Creative Commons license, and indicate if changes were made. 
greater public/individual access, while concurrently excluding, marginalising, and maintaining power relations (García-Jiménez, 2012). Higher educational degrees remain one vestige of social attainment, demarcating social status and class as we negotiate new ways of communicating and interacting. Although university degrees increasingly involve TMC, in Australia, the distinction between those obtained 'internally' versus entirely through 'distance education' (DE) persists despite the introduction of 'mixedmode' courses involving 'on-campus' and 'off-campus' study. Educational reviews note online learning continues to enjoy market expansion (Norton, 2017), yet it was government funding policy change that enabled Australian public universities to increase offcampus offerings and created such growth; "restraints have been removed, and we observe rapid growth in this market" (Kemp \& Norton, 2014, p. 58).

In this article, DE refers to degree completion using TMC without 'traditional', faceto-face classrooms and is used interchangeably with the term 'online learning'. Sometimes termed 'online education', DE is a delivery mode that, despite historical persistence and continued growth, retains a minority status. Historical data reveals all 'off-campus' Australian university enrolments between 1950 and 2013 accounted for $9 \%-18 \%$ of total enrolments (Norton \& Cherastidtham, 2014). For the most recent year reviewed, 2013, when 'multi-modal' courses are included, DE and mixed-modal study constituted $25 \%$ in contrast with $75 \%$ of internal, or 'on-campus' study in Australia (Norton \& Cherastidtham, 2014). Despite Australian degree and institutional 'quality' being strongly defended by 'online degree' marketing initiatives and university goals that symbolically support meritocratic visions of educational democracy and global access, DE remains socially stigmatised in ways commonly 'known', yet not academically investigated. In contrast, American research illustrates how the social stigma surrounding online degrees disadvantaged graduates. For example, employers chose to hire accounting graduates with lower grades from 'traditional', internal degrees rather than those with higher academic grades who completed online study, irrespective of the perceived quality of the university attended (Grossman \& Johnson, 2016). Noting the dearth of research examining hiring managers' perceptions about online degrees, interviews with private-sector hiring managers in Rochester, New York also revealed stigmatised perceptions with 33\% having reservations or negative views about online degrees (Cannon, 2014). Even graduates in disciplines at the forefront of online technologies, library science, faced American employers who expressed concern that online degrees are part of educational 'dumbing down' and preferred traditional graduates whom they perceived had better face-to-face skills and experience valuable for working in a library team environment (Chant, 2013).

In contrast with research focusing on employability, the present research explores DE students' experiences with, and perceptions of, studying online, documenting prejudices and benefits for the purpose of enhancing higher education experience and administration for all involved. A myriad of academic disciplines examining the affordances technological innovations grant, or deprive, reveal social interactions mediated by technologies not only have great power to stigmatise, but also to create and recreate the 'self' because who we are is deeply affected by perceptions and social meanings created through social interactions (Giddens, 1991). For centuries social theorists posited 'new' technologies as threats to social cohesion, connection, and functioning, with definitions of 'community' sociologically attached to notions of belonging, shared engagement, 
identity, and purpose (Chayko, 2014), as a wide array of theorists as diverse as Emile Durkheim and Robert Putnam purport. It is perhaps surprising, therefore, that much empirical and practical focus prioritises comparing and reproducing norms and experiences between online and face-to-face communication, particularly when discussing educational technologies. Bernard et al. (2009) argue direct comparisons of learningcentred interactions and communications between face-to-face and online environments are perhaps inappropriate at best, and misleading at worse, given the perceived change in effective teaching styles afforded by technology. Studies repeatedly associate online and e-learning with an impersonal nature, even as positive and negative emotions are expressed (Zembylas, 2008), in contrast with the highly didactic and contentcentred tendencies of traditional face-to-face learning.

Sociologically, demographics have long been used to establish and dispel stereotypical trends across cohorts using various technologies and communication forms. Demographics, however, fail to discern deeper questions examining what contemporary online learners construe to be key advantages and challenges of pursuing higher educational degrees when technologically-mediated learning is the only communication form offered. Social theorists have long noted the value non-verbal communication norms, symbolic meaning systems, gestures, behaviours, etc., play in negotiating successful social interactions (Garfinkel, 1967; Goffman, 1967). A dearth of research and conceptualisation, however, explores how CMC/TMC, whether synchronous or asynchronous, affect social interactions at micro-sociological levels. Sociological research reviews identify limited application of symbolic interactionism (SI), particularly Erving Goffman's theory, to mediated technologies because its relevance is construed as limited to face-to-face interactions (Rettie, 2009). Applying and extending SI, Rettie (2009) analytically compared UK interactions using mobile phones with telephones and letters, arguing mobile phones' synchronous nature shares multiple affinities with face-to-face interactions, such as being negotiated social interactions less amenable to being "ignored" (p. 432), in contrast with text-messages and other written forms where one's presentation of 'self' may be more privately controlled. Although relevant for mobile phone users, Rettie (2009) perpetuates theoretical biases and fails to surpass debating a/synchronous communication affordances, returning to classical definitions of 'social situations' to adjudicate micro/macro conceptualisations/applications and conclude synchronous interactions must "create an intersubjective social experience" and foster "collaborative interaction and coconstruction of an ongoing shared social situation” (p. 425).

In Australian higher education today, great emphasis is placed on fostering 'interactivity', with $\mathrm{CMC} / \mathrm{TMCs}$ foregrounded as pathways to engage online learners in manners analogous to internal learning. Such focus, however, also reproduces academic debates regarding communication affordances and, practically, produces learning technologies that seek to share greater affinity with face-to-face interactions, rather than innovatively transcend traditional communication norms/processes. CMC/TMC that occur where individuals perceive they have capacity, agency, to co-create online social environments, as embodiments of social order and reality in line with Garfinkel's (1967) classical sociological theory, offer examples where outdated dichotomisation between physical/TM realities may be transcended. Although Rettie (2009, p. 426) purports distinguishing SMS/texting and telephone conversations as a/synchronous communication events by using the SI criterion, "there is an encounter only if there is sustained focused interaction", analytical 
progress necessitates conceiving interactions occurring within $\mathrm{CMC} / \mathrm{TMC}$ environments as freed from temporal constraints historically imposed to determine embodiments of 'self'. As Rettie (2009, p. 435) notes, "synchrony is not mere technical affordance, but also depends on social expectations of immediate feedback and sustained, focused attention". Given sociological research documents the centrality of social interactions to higher educational experiences (Ragusa, 2007, 2009, 2010; Crampton \& Ragusa, 2012), examining online learners' 'social expectations' with CMC/TMC, rather than debating a/synchronicity, may advance issues of salience to higher education administration, such as 'successful' learning outcomes, degree completion, graduate 'attributes', and 'employability', as well as discerning academic knowledge gained from formal education delivered through different modes (i.e., internal, distance, mixed).

Recent sociological research reveals social interactions resulting from TMC embody a host of social expectations, notably the "social imperative" (Standlee, 2016, p. 15) demanding immediate presence, or, social availability. Social expectations that online communication, whether educational or social, will be received instantly places relentless communication demands, causes difficulty with students' boundary-creation/ maintenance, creates dependency, anxiety and, ironically, 'absence' from face-to-face interactions interrupted by TMC's intrusion as 'real-time' conversations are interrupted to respond to a Facebook or other 'instant' TMC/message as "hyper-connection" (Standlee, 2016, p. 19) becomes normative. 'Superconnected' (Baron, 2010), being always 'plugged-in' (Chayko, 2014), and 'fear-of-missing-out' (FOMO) (Przybylski, Murayama, DeHaan, \& Gladwell, 2013) are but a few maladaptive responses CMC/TMC yields. While TMC may be 'ignored' as one self-determines when/if response is desirable (Rettie, 2009), more recent research suggests the social expectations and implications arising from 'deviant' CMC/TMC responses share much in common with non-TM social interactions (Chayko, 2014; Przybylski et al., 2013; Standlee, 2016). Put simply, individuals feel compelled to respond to TMC and fear the consequences of not complying with $\mathrm{CMC} / \mathrm{TMC}$ social norms and expectations.

The present study commenced in light of these insights and sought to produce results of practical relevance to students and teachers using online environments for higher educational purposes. Whereas prior research concentrated on the quality of interactions, this article draws attention to prior research finding the quantity of online learning interactions may prove worthy of consideration as increased interaction may neither enhance performance, nor student satisfaction. With more than three 'types' of online interaction (email, forums, and lecturers) yielding no further learning advantages, particularly given time and cost considerations (Castaño-Muñoz, Sancho-Vinuesa, \& Duart, 2013), assumptions that 'more' communication is better demand critical thought. Further, while commonly assumed younger generations are technologically savvy, and therefore willing/able online learners, prior research finding technology attitudes and learning-resource awareness were greater predictors of usage than age and $86 \%$ of students were competent and effective technology users (Concannon, Flynn, \& Campbell, 2005) suggests experience is a better predictor of CMC/TMC attitudes/competency than demographics. Thus, the present study uses a qualitative, experience-driven focus to augment the plethora of research arguing the continued relevance of demographically-driven analyses to advance knowledge about educational technologies. 


\section{Methods}

Students enrolled in a 100-level DE subject were offered the opportunity to voluntarily complete a survey containing open- and close-ended questions for the purpose of exploring students' learning perceptions and lived-experiences. Opportunity was provided to complete the survey electronically or print/mail a hardcopy. Students received neither compensation nor educational privilege for research participation and the research design ensured participants' identity could not be determined. All surveys were submitted to a third party for de-identification and anonymous ID codes were used for data analysis. Both the survey and distribution method received Human Ethics Committee approval by the university. Close-ended questions permitted collection of limited quantitative data which was entered into SPSS for the purpose of demographically describing participants, not to conduct quantitative statistical analysis or determine causality regarding degree perceptions. To identify student perceptions and lived-experiences, a range of open-ended questions were posed. This article presents key qualitative findings for the open-ended survey question, What do you see as the major advantages and disadvantages of distance education as you have experienced it in this subject? Although participants' perceptions of DE learning experiences may be illustrative and/or indicative of broader trends, qualitative epistemology restricts extrapolation of findings beyond the present sample and aims to examine emerging themes in-depth rather than be quantitatively representative of broader populations (Cohen, Manion, \& Morrison, 2007; Neuman, 2011; Ragusa, 2012). A key advantage of qualitative research is its capacity to advance collective understanding of insights generated by research participants, rather than predetermined by researchers using close-ended answer options, thereby permitting unanticipated ideas to emerge for future examination/verification if localised findings are exhibited more widely, why, and how (Creswell, 2014).

Guided by existing research, theory, and conducted in an economic environment where Australian universities are seeking DE market expansion and growth, this study's research goal sought to document DE students' individualistic expectations and firsthand experiences at an Australian university renowned as a leader in online delivery. Undertaken in a sociocultural environment emphasising individual flexibility, choice, and the ability of technology to 'solve' the social problem of students having insufficient time, infrastructure (i.e., limited physical access to metropolitan or regional universities), and/or capacity to undertake face-to-face university education, the research design was informed by critical grounded theory (CGT). CGT is an ontology gaining increased recognition for its utility in explaining how individuals 'make sense of', or attribute meaning to, social interactions and phenomena experienced in complex organisations. This approach was chosen for its capacity to surpass the limitations of traditional grounded theory exhibited in Glaser and Strauss' (1967) classical theory, namely uncritically employing an 'a-theortical' approach to social research to conduct inductive research that surpasses limitations imposed by deductive scientific processes.

CGT enabled creating research questions that sought neither to confirm nor reject prior theories/research findings. Rather, it commenced from "critical observations and experiences of a social problem, of an issue or a process that she wishes to explain, because she recognizes the need for social change" (Belfrade, 2017, p. 259). Hence, awareness that prior research found CMC/TMC interactions systemically and individualistically exhibited 'FOMO' and 'superconnection' behaviors informed the data 
analysis, yet, did not restrict the research design to empirically testing the manifestation of such behaviours/responses. An inductive, grounded approach was applied to enable students to articulate what they considered benefits and disadvantages of online learning in higher education, allowing for fluidity of concepts. Conceptual fluidity was operationalized by creating an iterative coding system that did not categorize individual items as 'good' or 'bad' since the research aim was to identify emerging qualitative trends across participants' responses by generating qualitatively meaningful themes (Bryman, 2012; Corbin \& Strauss, 2008). Practically, for example, where students reported "no classes", "flexibility", and "study at my own pace" as either DE 'advantages' or 'disadvantages', these were coded "F" for "flexibility" as a key theme. Thus, while 'flexibility' tended to be perceived an advantage of DE, such perception depended on students' individualistic beliefs and experiences.

In-depth of thematic analysis was made possible by multiple data readings. Initial theme construction guided two further re-readings of all responses, with reflection and revision following each reading until the final thematic coding scheme suitably reflected participants' key perceptions, with great care taken to avoid introducing researcher bias (Marshall \& Rossman, 1999). For example, during the second iteration of the coding scheme, 'flexibility' emerged as a theme too simplistic to capture the diversity of responses and experiences/perceptions students conveyed across responses. Whereas initially flexibility appeared to be primarily related to 'time', several examples illustrated that online forums, while able to be accessed from anywhere and at any time, were perceived to permit a different type of communication, aside from being temporally different. Indeed, the technologically-mediated nature of online communication was thought by some to create miscommunication, thereby necessitating more communication than in face-to-face classrooms and, despite the ability for CMC/TMC to occur at 'any time', inevitably, academic replies to students' online questions were perceived to arrive insufficiently as soon, or immediately, as students wished. Furthermore, depending upon communication proficiency with written expression, some students found online communication more frustrating as they struggled to convey/receive suitable replies from peers/academics. Discursive complexity was one of many examples where a seemingly 'simple' issue, the 'flexibility' afforded by online communication, made the two categories 'advantage' or 'disadvantage' posed in the question unique to individual experiences. Moreover, single students reported times when they both appreciated and despised having 'no classes', so even perceptions of single issues by the same person were at times context-driven and not absolute. For example, some reported the only way they could undertake university study was without having to attend face-to-face lectures even though they felt they were missing out on such experiences as a DE student.

To accommodate such tensions exhibited in the data, analytical priority was given to identification of qualitative content-driven theme construction, rather than dichotomise/categorize responses as 'advantages' or 'disadvantages' in the final coding scheme. Using the example 'flexibility', this practically resulted in allowing responses to be recoded based on individually-described context, rather than use a content analysis process whereby appearance of a single keyword determined which category/code to employ. This process, while more time consuming, ensured the themes better represented the data, enhancing reliability. Three content-driven final coding scheme 
themes, Superiority of face-to-face interactions and FOMO, Communication immediacy and learning anywhere, and Technologically connected, yet socially isolated were created to express the major emergent trends across individual responses and document overlap. This method permitted the research focus to remain consistent with the research aim of documenting pervasive issues/perceptions illustrating why students were satisfied or dissatisfied, while allowing for divergent perceptions about the same item identified, i.e. 'no classes', to be accurately coded based on students' sentiments/experiences. Findings are presented in the next section using anonymous identification codes to nonexhaustively offer examples of specific surveys and/or data quotes illustrating each theme.

\section{Findings}

Demographically, the majority of the 289 students who completed the survey were female (80\%). Consistent with broader DE demographic trends, most (87\%) were mature-age students (over age 21) and concurrently studying while employed (78\%) in full-time $(44 \%)$ or part-time $(34 \%)$ jobs while most $(62 \%)$ also juggled family responsibilities. Of the $56 \%$ who were parents, $13 \%$ were single-parents. A sizeable group (41\%) reported working between 35 and $80 \mathrm{~h}$ a week, exceeding the Australian maximum 38-h workweek for full-time employees stipulated by the Fair Work Act 2009 (NSW). Predominantly (88\%) were in their first or second year of their degree, English was largely (97\%) their primary language and most (87\%) were born in Australia or New Zealand. Birthplaces of the remaining 13\% were very diverse, including Europe $(n=26)$, Asia $(n=7)$, North America $(n=6)$, Middle East $(n=1)$ and South Africa $(n=1)$, and 22 distinct ethnicities/cultures were identified.

Thematically, three key trends emerged from qualitative analysis of the open-ended question exploring student perceptions of distance/online learning: a) Superiority of face-to-face interactions and FOMO, b) Communication immediacy and learning anywhere, and c) Technologically connected, yet socially isolated.

\section{Superiority of face-to-face interactions and FOMO}

Students overwhelmingly (85\%) perceived traditional internal classrooms offered a better outlet for communication than online learning environments. Online education was repeatedly described in contrast to what it lacked. Normative expectations of higher education were guided by, and derived from, internal classroom experiences. Not being able to attend lectures (ID86), lack of face-to-face instruction (ID88), no face-to-face interaction (ID41; ID24), and no face-to-face discussion (ID11) are responses exemplifying perceived disadvantages of DE. Further, $64 \%$ thought their academic learning would be better if they were in 'traditional' classrooms. Had I been given the chance to attend classes it would be a great opportunity (ID69) described a 40-year-old born in Lebanon living in Sydney. The following quote offers insight into criteria students commonly used to evaluate their online learning experiences:

Nothing beats the face-to-face communication with student/lecturers or the tutorial/ library resources that attending university brings ... the same resources are not available to DE students, especially face-to-face with lecturers. For that reason employers assume obtaining a degree through DE does not carry the same weight. (ID240). 
The perceived disadvantages of online learning, where all communication was technologically-mediated, were complex and seemingly contradictory in several instances. With online interactions the only type of learning-related communication possible, a sense of 'missing out' emerged. Two broad types of 'missing out' were perceived. On one hand, students feared they would miss out on lectures (ID101), specifically internal lectures which they thought provided discussion opportunities lacking in DE, even when electronic lectures were provided in their DE subject. Missing out on conversations about a topic (ID248) was perceived a major disadvantage of DE despite online conversations about subject-content being made available 24/7 through electronic forum discussion and chat opportunities and provision of teacher-student and student-student online communication/interaction opportunities. Interestingly, this same student exclaimed she didn't anticipate so many opportunities for online discussion and assistance (ID248). Although the lecturer was available for the same quantity of time for DE student consultation as for internal students, the perception pervaded across individuals that online communication did not 'count', or qualify as on par with face-to-face interactions. In sum, regardless of pedagogical structure, DE learning opportunities were perceived as quantitatively different.

\section{Communication 'immediacy' and learning 'anywhere'}

Students perceived different socio-physical boundaries existed between internal and DE study utilising online learning. DE students perceived internal lectures occurring in fixed times/spaces constituted 'normal' higher education, rather than construed them as an outdated or disadvantageous learning mode. Students unable to meet the demands of internal study exhibited victimised individualism by accepting their personal circumstances were at-fault, rather than expecting universities to better accommodate mature-age students' availability for face-to-face learning. Conversely, online learning was held to disproportionally rigours temporal standards. Despite asynchronous online forums being available 24/7, and synchronous chat available at designated times, the unavailability of on-demand synchronous communication with lecturers to accommodate individual learning needs was highlighted as lacking and disadvantaging students' learning. Not being able to talk to [the] lecturer (ID247) whenever any student personally desired was a limitation noted by one under-20 Sydneysider. Such sentiments traversed student age, however, as mature-age students, such as a student living on 'the coast' who lamented the inability to ask 'on the spot' questions (ID250) when studying by distance, reflected similar perceptions. Although occasionally students listed lecturer quickness in responses (ID73) as an advantage of online learning, more commonly the response rate of lecturer-to-student online communication was perceived as too slow. Responses were expected from DE lecturers within minutes of students' typing forum postings or emails. Discourse used, such as needing 'immediate' replies, reflected different communication expectations than those found in traditional classroom environments where hours or days intervened between student/lecturer interactions. Inability to further clarify immediately (ID250), not able to get immediate assistance from a teacher (ID239), lack of immediate discussion of material (ID88), and it takes time for e-mails/phone call to be returned (ID254) are examples reflecting expectations of immediate communication with online enrolment. 
Sentiments chastising the immediacy of lecturer reply coincided with the prolific identification of learning at my own pace (i.e. ID249; ID256; ID258; ID239; ID240; ID245; ID101; ID118) and capacity to study at home in your own time (ID246; ID21) as the greatest advantages of DE and online learning, often by the same students. Expectations existed that no rigid time constraints be placed upon students by learning activities; students' time ought not to be obstructed for any reason, particularly demands to participate in synchronous online communication, assessment completion, or exam preparation. Such perceptions reflect online degrees as a consumer product whereby interaction demands, much like customer satisfaction, are perceived unidirectional. Although students associated DE with learning from anywhere and perceived advantages included more freedom, working from home, being with family and pets, ability to complete [a] degree in [a] rural town and not having to sit in noisy, disruptive classroom[s] (ID255), they were unwilling to accept the many perceived disadvantages of communicating electronically yet simultaneously wanted to be able to access all the same resources and opportunities (ID249) as internal students. While eschewing systemic imposition of time constraints, some found DE's flexibility disadvantageous, noting with online there is less routine, means MORE discipline, less access to library and resources, less socialization (ID255).

While technology has enabled online learning to grow into mass education, students who modelled communication and interaction experiences on face-to-face classroom experiences were among the most disappointed. A 43-year-old therapist with many caretaker responsibilities for both infirmed parents and children bemoaned, in my past experience 4-8 years ago the lecturer was supported and seem to know the students. They were flexible for assignments...330 students is too many to do this with. The attention has to be impersonal and patchy (ID96). In this example, the student's expectations greatly surpassed the institutional time and resource provision conveyed in university online learning policies.

A degree of 'exceptionalism' also emerged whereby online learning was simultaneously thought to require special consideration of individuals' non-academic life commitments and provision of a communication environment on par with internal educational experiences:

That you are supported by your lecturer and the university in a staged learning pattern to develop the skills and integrate the knowledge and understand the materials as are the internal students. Recognition needs to be given to the special work and family commitments of distance students over and above those studying internally. To do this you require extensive written materials to work from, guided forums to discuss ideas relevant to that week's material as internal students have in tutorials. Discussion by phone to clarify issues and misunderstandings ... working together to provide alternative views with just as much debate, information and pop quizzes to assess understanding and being on the right track as internal students. (ID96).

Where face-to-face, traditional classrooms remain normative in guiding learning expectations, re-socialisation may be required to better match student expectations with capacities possible in online higher education learning environments, particularly in a consumer culture: 
I think my attitude is shaped by the fact that I know I pay the same fees as internal students so I expect similar treatment. Obviously we cannot have face-to-face lectures, but I do expect to receive an experience as close to this as possible...given that most $D E$ students are part-time and time-poor compared to full-time internal students, it seems to be the wrong way around. (ID73).

Individual experiences, resilience, living conditions, and other factors affected individual attitudes and expectations. In several instances, the same quantity and type of online communication experiences were perceived as vastly different. For example, a single 47-year-old health care worker from New Zealand reported, I found the online information, lecturer and thoughts of others on the subject inspiring and spurred me to learn more as well as search on the Internet for information (ID98), much like a 47year-old male from England who noted no disadvantages and found online communication and learning to be very satisfying...I have come to really appreciate the value of this Internet campus despite the subject was his first foray into Internet study (ID97). In contrast, a 36-year-old Australian receiving the same online learning experience who worked $60 \mathrm{~h}$ a week and had caretaker responsibilities expressed several dissatisfied comments, noting lack of class/student interaction, lack of teacher input, lack of teacher availability and misinterpretation of what is being said in forums due to lack of face-toface contact (ID71). Hence, categorizing specific CMC/TMC and/or educational technologies as 'advantageous' or 'disadvantageous' appears futile given the relevance of individual perceptions, expectations, and experiences with the same DE environment, learning activities, and academic support resulted in highly divergent responses.

\section{Technologically connected, yet socially isolated}

Online learning frequently failed to yield a sense of 'connection', despite multiple platforms available for online interactions with peers, academics, and administrative staff. Even when assessments were structured to foster online communication, students expressed not having a personal connection with peers (ID249), no direct contact with lecturer (ID44), no face-to-face contact (ID20; ID22), no face-to-face access with lecturers (ID8), and no personalised teaching as a 39-year-old full-time social worker, 40year-old office manager, 35-year-old supervisor, 26-year-old business coordinator and 32-year-old communications officer all commented along with a multitude of others. Although marketed to enable students to combine studying with employment and/or other responsibilities, online communication often was perceived inadequate for learning and/or meaningful connection with peers and lecturers. A 46-year-old female born in Holland expressed frustration with not being able to interact with others for clarity (ID50) and a 33-year-old male law enforcement officer born in India described the learning mode as less humane (ID57). Neither the provision of lecturer-created online lectures, nor teacher-student and peer-peer online discussions proved sufficient as communicative opportunities to avoid generating the perceived disadvantage that $\mathrm{DE}$ offered no teacher/student relationship (ID258). This occurred even when individuals 'strongly agreed' to statements such as 'my personality is well-suited to DE' and 'online lectures helped me to learn the information better' and thought everything was actually quite well set out and I found it simple (ID258). Indeed, for this 20-year-old male 
student, like many others, online learning meant, education for those who lives a great distance from the University (ID258). For others, such as a 35-year-old Canadian male living in Melbourne, it was not physical geography, but rather the attempt to combine working 6 days a week in $12 \mathrm{~h}$ shifts at the time (ID87) while undertaking a university degree in order to change careers that proved most challenging and, perhaps unsurprising, led to feeling, it's tough to stay motivated (ID87).

DE was undertaken not for its unique capacity, attributes, or difference with face-toface classrooms, but rather as a 'necessary evil' due to rurality, caretaker responsibilities, financial restraints, and other life circumstances. Isolation (i.e. ID258; ID254; ID261; ID267; ID239; ID241; ID68; ID43; ID29; ID21; ID7; ID5 ID1) was a notable disadvantage profusely articulated and transcended individual demographics. Face-to-face interactions were perceived as the only type of communication with capacity to mediate social isolation. Unfortunately, neither the quantity nor type of online communication offered was sufficient to mediate some students' feelings of social isolation, with expressions such as feeling isolated alone as don't meet fellow students in person (ID239) conveying the depth of experience. Reflecting on the provision of audio recordings from the same subject's internal lectures, a full-time disability support worker from Sydney described, I was just an outsider listening to number of interactions between others which I had no part in (ID261). This student, like others who perceived loneliness (ID15) as a key disadvantage, found DE to be a lonely experience, regardless of the quantity and type of $\mathrm{CMC} / \mathrm{TMC}$ interactions, and elaborated it is hard to gauge progress without peers around (ID261).

Online interactions often were considered insufficient to self-assess academic progress or suffice as peer-learning interactions. Comments such as hard to compare myself to others to see how I'm performing (ID264) and no study groups available (ID101) were offered despite students receiving reports about the cohort's academic performance on assignments, and online discussions, exam preparation, and study groups being offered. Despite most perceived online communication and interactions to be isolating and inferior, with in-class interaction [a] better way to learn (ID74), the sentiment was not universal. I found the forum to the best place to learn and to get help when needed (ID75) wrote a 41-year-old woman born in Bosnia. To her, DE meant learning independently. I am self-motivated and I like to work at my own pace (ID75). Likewise, another 41-year-old, Australian-born woman said she loved...DE and wouldn't have coped emotionally on-campus. I didn't at school! (ID70). Generally, self-motivated students appeared more satisfied with DE.

Enrolment in online subjects failed to prevent lack of face-to-face interactions to be listed as the 'worst' disadvantage. This occurred irrespective of location, with urbanites as dissatisfied as rural students. Lack of face-to-face help (ID244) noted a 30-year-old from Brisbane, Don't meet actual people/lecturers wrote a 33-year-old from Sydney and No one-on-one contact (ID251) proclaimed a 30-year-old child care worker from Melbourne; the use of multiple/diverse TMC modes were perceived inadequate to meet online students' communication needs and interaction expectations. In contrast with the commonly stereotyped universal appeal of attending face-to-face lectures, virtual classrooms and interactive online teaching platforms were considered suitable for only some types of students. Analysis revealed varied student comfort and confidence with online communication. I did not post on the forum very much...I needed to be 
comfortable using the forum (ID102) and I was infrequent on chatting on the forum but I was always on looking at people's questions and [lecturer's] responses. I wouldn't have been able to complete it [the subject] otherwise (ID87), contrasted with, I checked the forum nearly every day being a compulsive type! (ID98), I access the forum on most days and find it extremely helpful! (ID72), and everyday when possible (ID97). Additionally, 'older' DE students assumed no younger students were studying by distance, despite nearly a third of students enrolled in the subject were under thirty due to their chosen degree offering several subjects only online, students' geographical location, or simply their lifestyle choice. Despite such 'realities', online learning at times was perceived a compensatory offering for seniors, the University attempts to negate university education being provided only to young school leavers...or even to those that are subconscious of being older than the majority on campus (ID100). Generational intolerance and stereotyping also emerged, with the following quote demonstrating how TMC may yield qualitatively similar and different types of interactions as face-to-face classrooms:

I found the forums to be used by two certain students that seemed to take over the forum and their continually flood of the forums with their thoughts and opinions... the forum has a lot of mature age student use it and it is sad to think that many of us would not post due to these two students. It is also worrying if these two students are mature age as their behavior didn't show that of mature age students. (ID71).

\section{Discussion and conclusions}

Despite communication technologies, economic efficiencies, and geographical restrictions encouraging increased university degree completion entirely through online/distance education, traditional norms associating high quality education with face-to-face learning are perpetuated by employers (Cannon, 2014; Chant, 2013; Grossman \& Johnson, 2016), administrators, and researchers (Rettie, 2009), resulting not only in continued comparison of these modes, yet quality being defined by 'traditional' classroom standards. Although other research notes direct comparisons are inappropriate and/or misleading (Bernard et al., 2009), and online education surpasses and/or shares similarities with traditional education (Zembylas, 2008), stereotypes persist about who is technologically proficient (Concannon et al., 2005). Furthermore, much practical activity aims to increase students' online interactions despite research finding more TMC may fail to be desirable or useful to learning outcomes because interactions' relevance to learning goals matters most to students (Crampton \& Ragusa, 2015). Hence, the present study's goal sought to shift focus away from comparing student demographics and/or study modes towards analysing student perceptions of online learning experiences. This goal permitted examining TMC using a 'micro' sociological lens and in light of known maladaptive psychological responses, namely anxiety stemming from feeling too connected (Baron, 2010; Chayko, 2014; Standlee, 2016) to fearing logging off will result in missing out (FOMO) (Przybylski et al., 2013).

To achieve the research goal, the present qualitative study examined what undergraduates completing an online introductory subject perceived were key advantages and disadvantages of DE based upon their lived-experiences. Thematic analysis permitted identification of three broad themes. The first theme reflected beliefs about the superiority of face-to-face learning interactions with peers and lecturers and a fear-of- 
missing-out on 'real'/ 'internal' classroom experiences non-DE students were receiving for the same tuition. Second was the perception that TMC, particularly with lecturers, needed to be immediately received by students, yet not reciprocally expected by lecturers of students who were paying customers. The importance of flexibility students' expectations/requests, including the capacity to 'learn anywhere' were valued advantages of DE, yet countered by having to be inconvenienced by 'irritating' TMC from peers. Finally, while students' felt they were always online, technology failed to ameliorate the social isolation online learning encultured. Findings highlight the importance of rejecting notions of who the 'typical' DE learner is and point to the urgent need for systemic consideration of how and what institutional communication practices and preferences are considered most desirable and why. Perceptions of CMC/TMC illustrated normative expectations that online learning ought to mirror stereotypical face-to-face interactions in internal classrooms, regardless of technical capacity or experience. Students' lived-experiences demonstrated online academic communication was perceived enabling degree completion albeit inevitably was an inferior substitute for face-to-face learning, perpetuating broader social norms and biases that CMC/TMC are poor 'substitutes' disadvantaged individuals must try their best to cope with as they 'miss out' on 'real' classroom experiences.

Collectively considered, examples across the three major themes highlight individualistic perceptions about DE and expectations of online learning experiences guided whether students felt they were 'missing out' on 'better' quality internal subjects, or, were advantaged by the unique opportunities afforded by online study. Regardless that, systemically, internal and DE students received the same quantity of academic time, the same learning materials, and the same pedagogical opportunities, beliefs derived from deep-seated social norms that learning occurs best in physical classrooms was mentioned repeatedly by students identifying the absence of face-to-face experiences as the major disadvantage of DE. Without re-socialisation processes in place to counter/disrupt normative biases and stereotypes, namely that 'internal' learning is the golden standard and DE its poor cousin irrespective of empirical evidence, educational technologies will be held accountable to a mythological image of an 'ideal' classroom. DE students overwhelmingly believed technologically-mediated lectures and tutorials, including those involving online discussions, did not produce interactions that enabled debate, clarification, and learning experiences on par with internal education, despite the equal cost of their degree. While universities continue investing in educational technologies aimed at providing 'comparable' learning experiences for internal/online students, findings suggest without equal effort expended to evidence and identify how learning content, resources, and interactions are analogous with face-to-face learning, hegemonic assumptions of 'digital dualism' (Jurgenson, 2012) will continue to emphasise differences. Thus, future research is required that evidences the equality of online and internal academic degree content and educational achievement so stereotypes about difference, and subsequent stigmatization of DE, is confirmed or refuted, rather focus on increasing online interactivity or replicating face-to-face interactions in online environments.

Social expectations and norms about educational technologies mirrored social media interactions; online students exhibited heightened expectations of 'immediacy', personalisation, and FOMO in their online study, lending further evidence of a 'superconnected' society where $\mathrm{CMC} / \mathrm{TMCs}$ produce temporal demands atypical of face-to-face 
interactions and yield different types of social anxiety (Baron, 2010; Chayko, 2014 Przybylski et al., 2013; Standlee, 2016). With 'soft' social skills, particularly effective communication skills, a highly sought graduate attribute (Nagarajan \& Edwards, 2014), findings highlight need to prioritise developing tacit skills required to be 'successful' online communicators, and correspondingly, online learners. Without prior DE experience when admitted, students were left to model prior learning experiences from face-to-face high schools or community colleges. Leaving undergraduates to 'figure out' how to be online learners exposes universities to unnecessary risks (i.e. student attrition, 'flaming', stress leave, etc.). With few expectations and little or no experience, it is unsurprising students felt ill-equipped in online interaction skills and findings contribute to research identifying improved access to learning support is a key factor in students' preference for face-to-face over online modes (Bailey, Ifenthaler, Gosper, Kretzschmar, \& Ware, 2015; O’Neil \& Sai, 2014). Complimenting Lee's (2010) crosscultural study of North American and Korean students, which found a positive relationship between perceived quality of online support and student satisfaction, students' perceptions and expectations about the quality, and quantity, of online learning support (from peers and lecturers) affected their overall satisfaction; no students who articulated they were dissatisfied with online learning experiences said expectations were met.

In addition to student-identified challenges, discrepancies between individualistic and systemic priorities warrant further consideration. For example, students believed online learning ought to permit completion of assessment items, subjects, and degrees at their [students'] own pace. This was understood as being around students' personal, work, family, and vacation commitments, an interpretation that differed from university deadlines and policies regarding equity, completion timeframes, and academic workloads. Improved mitigation of competing interests and decreased misinterpretation may be achieved by establishing clearer guidelines that are consistently communicated and applied across subjects, courses, and degrees. Likewise, clearer articulation of what tuition 'pays for' may prevent inaccurate perceptions, and hence customer dissatisfaction, that one learning mode receives 'more' for the money than another. Given the lack of transparency relevant to learning mode expectations, teaching methods, workloads, and assessments were identified as factors affecting enrolment decisions and changes at another large Australian University (Bailey et al., 2015). This study lends additional evidence that ambiguity and varied student/lecturer interpretation about what constitutes effective/sufficient 'online learning' contributes to student dissatisfaction and FOMO. Clear and definitive academic leadership is, therefore, required to clarify what distance, internal, and/or mixed/blended education institutionally mean and ought to be provided to students prior to degree commencement as well as extended to staff and students in alignment with institutional goals and capacity.

Perceived difference in the quality of face-to-face and TM-interactions was the greatest, and most consistently agreed upon, disadvantage students noted for online learning; TMC, whether emails, asynchronous/synchronous forums, virtual lectures, phone-calls, or electronic announcements, were deemed inferior to face-to-face conversations. Regardless of the convenience (ID13) electronic communication permitted, DE students simply failed to believe interactive online platforms were a suitable substitute for 'real' human interactions. Face-to-face interactions, unlike TMC, were perceived motivational and thus crucial for academic learning. You have to continually motivate 
yourself to read and study (ID10) was the fundamental lesson online students learned. Findings revealed most students felt internal is better; with distance, you are not pushed to your ability so can slacken off (ID131), suggesting poor self-motivation may continue underscoring the high online study attrition rates experienced by early online courses (Muilenburg \& Berge, 2005). Technological advances appear not to have appropriately addressed this issue as the perception that face-to-face interactions enhance learning motivation perseveres. Nevertheless, this may have less to do with learning mode than with individualistic capacity to personally contextualize a lesson/assessment's importance as Hartnett, St. George, and Dron (2011) found extrinsic motivators, particularly a learning activity's perceived value, were as important as characteristics normally associated with intrinsic motivations (e.g. task enjoyment) often associated with self-efficacy.

To better understand why/how online and face-to-face learning affect academic success in Australia, future researchers may benefit from deeper examination not only of demographics, but also of academic performance, study mode, and degree completion. Community college students studying online have been found more likely to fail or withdraw than those studying internally according to large American studies of 21,000 and 54,000 students (Jaggars \& Xu, 2010). Likewise, others found some students initially studying by DE or online in the first two years, such as the students in this study, were less academically prepared than those enrolled in face-to-face classrooms (Shea \& Bidjerano, 2014). Further, community college students studying online or completing online coursework were less likely to complete a degree or transfer to a four year college (Xu \& Jaggars, 2011). Demographic attributes prior research indicates may increase the likelihood of effective online learning, specifically "highly motivated, "mature age" students" (Bacow, Bowen, Guthrie, Lack, \& Long, 2012 p. 18), require deeper examination beyond quantitative description given the present study suggests self-motivated students appeared more 'satisfied', yet simply being 'mature age' may fail to either increase online learning success or satisfaction. Age-based stereotypes emerged among students that, at times, thwarted positive TMC interactions as students made assumptions about classmates based upon the little demographic information derived from online postings. Thus, in distilling what and how many communication opportunities to offer, and for what pedagogical purpose, age-based stereotyping is exceedingly problematic. Although some students stereotyped others in their own and others' generation, meta-analysis of qualitative comments revealed little variation in technical competency or preference for TMC in online learning, countering notions that younger generations are more technologically able or willing online learners and adding support for the valuable role social attitudes play in willingness to use technology (Concannon et al., 2005).

Consistent with prior research finding 'traditional' internal classroom environments resulted in greater student learning than purely virtual classrooms (Concannon et al., 2005), this research highlighted students' self-reported tendency to 'slacken off' without face-to-face learning. Some perceived certain personality types were better suited to DE, especially those with negative internal classroom experiences, yet the majority felt they had little choice other than online degrees due to life circumstances. This logistical aspect of mode choice has, understandably, been a consistent finding in the literature (Bailey et al., 2015). When logistics is not a determining factor, as was the case for most participants, then students' degree of subject-content interest may affect 
their satisfaction and expectations given several studies have found students prefer to study topics they find harder or interesting in face-to-face classrooms (Jaggers, 2014; Artino, 2010).

In contrast with suggestions that Internet access has translated into greater interaction in online learning (Bernard et al., 2009), present findings suggest the level of interaction experienced, either peer-peer or student-teacher insufficiently met DE students' expectations. Finding that TMC did not match preferred levels or expectations mirrors Gosper, Malfroy, and McKenzie's (2013) findings from a survey of over 10,000 internal students in three Australian universities. With desire for interaction and connection noted as the major decisive factor for students with the option of studying face-to-face or online (Bailey et al., 2015), TMC is heralded as the primary way to improve DE student engagement at most Australian universities. Indeed, another study from the same institution as the present study found students regarded online tools that promoted interaction with their teacher were the most important among the plethora available (Small, Dowell, \& Simmons, 2012). Likewise, absence of suitable levels of interaction with and connection to peers and teachers was described by North American distance students (Otter et al., 2013).

Despite cries for increased/enhanced student-teacher interaction, a contradictory scenario emerged whereby DE students' simultaneously desired more synchronous communication opportunities while eschewing any activity imposing time constraints inhibiting studying at their own pace. In reality, provision of multiple TMC platforms and opportunities generated anxiety about how to fit higher communication loads into their already over-loaded lives, aligning with research showing resentment with learning activities, such as synchronous online classrooms or virtual worlds, and frustration, rather than appreciation, from a social group overly preoccupied with maintaining flexibility (Boling, Hough, Krinsky, Saleem, \& Stevens, 2012). Thus, a 'catch 22' scenario emerges whereby institutions are faulted for providing insufficient synchronous communication opportunities and DE students lament the lack of face-to-face engagement experienced in internal classrooms, yet DE students are unwilling to sacrifice flexibility or independent control of their time. Despite the continued growth and ongoing changing nature of DE (Eom, Wen, \& Ashill, 2006), findings suggest student satisfaction was increased neither by the quantity nor type of TMC opportunities offered.

Drawing upon DE students' first-hand, lived-experiences with online study, this article documented what learners perceived facilitated or thwarted their learning process and what expectations they held for themselves, their teachers, and higher education institutions more broadly. Findings revealed students thought communicative, not technical, proficiency, mattered most to academic 'success' in online environments. Results suggest organisational and academic quests for 'interactivity' and 'engagement' in online higher education environments (Croxton, 2014; Smith \& Winking-Diaz, 2004) may benefit from shifting focus towards creating learning environments that embody effective time management through educational design and organisational health and safety imperatives, rather than demand 'social interaction' through forced online communication. Students perceived too much online communication negatively affected online subject and degree completion. Thus, finding the 'right' balance between 'too much' and 'too little' communication remains a challenge demanding future research. Questioning organisational imperatives for increased online student/teacher interaction, 
without thorough investigation of its academic purpose, may also assuage and/or prevent negative academic workload implications arising from maladaptive responses to $\mathrm{CMC} / \mathrm{TMC}$, namely increased academic stress leave and anxiety encultured by perceptions of '24/7' workloads (Gregory \& Lodge, 2015). Educational technologies may facilitate realisation of meritocratic ideals for online higher education (i.e. enhancing flexibility, surpassing sociocultural barriers/inequities, promoting educational pluralisation) by creating adaptive learning environments that proactively create realistic expectations, minimise anxiety-producing behaviours, and promote successful subject, and subsequently degree, completion.

Bridging the many gaps qualitatively manifested - generational, socio-economic, gender, geographical, cultural, and socio-psychological - demands an interdisciplinary lens. Students who disclosed trying to simultaneously cope with mental illnesses, undertake primary caretaker responsibility for parents with dementia or six children, perform $60 \mathrm{~h}$ of shift-work weekly, re-integrate into a new culture after migrating, or undertaking a host of other otherwise 'hidden' life activities revealed there is no such thing as a 'normal' distance student, even as many believed internal students had perfectly carefree lives. TMC makes largely invisible our 'real' selves; what is communicated electronically is what the speaker wishes to reveal. Symbolic gestures, expressions, and emotions communicated through the physicality of face-to-face interactions may, therefore, enable students to 'learn' more than academic content. If and how academic learning is differently affected by the 'real' presence of individuals, in contrast with similar but different online expressions, remains unknown. Hence, it is imperative institutions unpack the complex relationship among economic, social, and demographic variables in determining cost-effectiveness of higher education delivery modes, pedagogical quality, and communication norms or guidelines. No economic advantage exists for poorly planned online environments resulting in impoverished student experiences that reduce the likelihood students will continue their degree (Artino, 2010). Technologicallymediated learning environments require deeper critical review and analysis to articulate and understand implications arising from heightened reliance upon, and presumed desirability of, TMC as a principle method of higher education delivery.

Finally, this research suggests the association of 'technology enhanced' education with the development of 'higher order skills' (Hardy \& Bower, 2004) may have more to do with the style and purpose of communicative and interactive activities pursued through learning, rather than a priori aspects of CMC/TMC as inordinately different from face-to-faceinteractions. Applying social media theory, 'digital dualism' (Jurgenson, 2012) drives many educational technology assumptions and much research. Namely, there is a tendency to accentuate differences between online/offline experiences. If one expects great differences between DE and internal learning, social norms stigmatise DE degrees, and perceptions/ expectations of educational technologies are informed by face-to-face-interactions, then academic learning and subject/degree completion may be stymied. Moreover, the affordances of educational technologies may not be fully realised.

Today's service-oriented, knowledge-based society requires high competency in 'soft skills', professionalism in interpersonal relationships, communicative competency, and awareness of cultural norms and their impact (Hendarman \& Tjakraatmadja, 2012). The greater interaction deemed necessary for successful online teaching (Desai, Hart, \& Richards, 2008; Dixson, Greenwell, Rogers-Stacy, Weister, \& Lauer, 2017; 
Richardson, 2017) could, therefore, be promoted as an advantage of online education. Creating 'successful' online communicators/learners, however, requires more than skill development. Prior research found having to communicate with peers using 'written discourse', a communication style perceived as a new and unfamiliar, created the greatest anxiety among students new to online learning (Zembylas, 2008). The present study also found students' perceived 'confidence' in their ability to communicate about subject content to peers was a barrier to online participation. Interactive online study may be an effective social environment for developing the communication skills required in today's digital society, yet social norms and perceptions appear to be historically informed. Clearer articulation of how online interactions enable subject content learning and preparedness for contemporary society must be accompanied by research evidencing specific learning modes (i.e., internal and online) achieve didactic outcomes of disciplinary and broader relevance. Comparative analysis of internal and DE students' comprehension of fundamental academic concepts, for example key psychological theories for psychology majors could help dispel or confirm perceptions that delivery mode drives learning outcomes and degree quality. Further, comparison of 'soft skill' acquisition (i.e. writing and communication skills) among modes (internal, mixed, distance) could also identify if and why some modes may be better suited to specific courses, rather than economics driving subject mode and other administrative decisions. By evidencing equity of degree rigour and learning outcomes we may eliminate the stigma pervading online degrees and better ensure hiring managers' preferences are informed by graduates' skills, rather than concerns about degree quality (Cannon, 2014) or perceptions that DE is a 'dumbed down' education option (Chant, 2013). As industry leaders, DE providers must take leadership in evidencing and ensuring equity in the quality, and capacity of, their educational products and graduates.

Acknowledgments

The author would like to acknowledge the research support received by Dr. Andrea Crampton during the research conceptualization process and formally thank the many undergraduate students who shared their 'first hand' experiences and thoughts about challenges and successes with online study for the benefit of future students, higher education providers, and researchers worldwide.

Funding

Not applicable

Declarations

This study was approved by the CSU human ethics committee. There were no competing interests and the study was unfunded. Due to ethics limitations, data is not available for public viewing.

Competing interests

The author declare that he has no competing interests.

\section{Publisher's Note}

Springer Nature remains neutral with regard to jurisdictional claims in published maps and institutional affiliations.

Received: 17 May 2017 Accepted: 3 November 2017

Published online: 20 November 2017

\section{References}

Artino, A. R. (2010). Online or face-to-face learning? Do exploring the personal factors that predict students' choice of instructional format. Internet and Higher Education, 13, 272-276 https://doi.org/10.1016/j.iheduc.2010.07.005.

Bacow, L.S., Bowen, W.G., Guthrie, K.M., Lack, K.A., Long, M.P. (2012). Barriers to adoption of online learning systems in U. S. higher education. Retrieved from: http://www.sr.thaka.org/wp-content/uploads/2015/08/barriers-to-adoption-ofonlinelearning-systems-in-us-higher-education.pdf. Accessed Apr 2017. 
Bailey, M., Ifenthaler, D., Gosper, M., Kretzschmar, M., \& Ware, C. (2015). The changing important of factors influencing students' choice of study mode. Technology, Knowledge and Learning, 20, 169-184 https:/doi.org/10.1007/s10758-015-9253-9.

Baron, N. S. (2010). Always on: Language in an online and mobile world. New York: Oxford University Press.

Belfrade, C. (2017). The gentle art of retroduction: Critical realism, cultural political economy and critical grounded theory. Organization Studies, 38(2), 251-271 https://doi.org/10.1177/0170840616663239.

Bernard, R. M., Abrami, P. C., Borokhovski, E., Wade, C. A., Tamim, R. M., Surkes, M. A., \& Bethel, E. C. (2009). A meta- in distance education. Review of Educational Research, 79(3), 1243-1289. 10.3102/0034654309333844.

Boling, E. C., Hough, M., Krinsky, H., Saleem, H., \& Stevens, M. (2012). Cutting the distance in distance education: Perspectives on what promotes positive, online learning experiences. Internet and Higher Education, 15, 118-126 https://doi.org/10.1016/j.iheduc.2011.11.006.

Bryman, A. (2012). Social research methods, (4th ed., ). Oxford: Oxford University Press.

Cannon, T. T. (2014). Perceptions of hiring managers regarding employment candidates with earned online degrees: Implications for the employability for graduates of online programs, Unpublished doctoral thesis (). Minneapolis: Capella University.

Castaño-Muñoz, J., Sancho-Vinuesa, T., \& Duart, J. M. (2013). Online interaction in higher education: Is there evidence of diminishing returns? The International Review of Research in Open and Distance Learning, 14(5), 240-257 http://dx.doi.org/10.19173/irrodl.v14i5.1336.

Chant, I. (2013). As online degrees become more prevalent, questions linger. Library Journal, 138(18), 23.

Chayko, M. (2014). Techno-social life: The internet, digital technology, and social connectedness. Sociology Compass, 8, 976-991. 10.1111/soc4.12190.

Cohen, L., Manion, L., \& Morrison, K. (2007). Research methods in education, (6th ed., ). NY: Routledge.

Concannon, F., Flynn, A., \& Campbell, M. (2005). What campus-based students think about the quality and benefits of e-learning. British Journal of Educational Technology, 36(3), 501-512 https://doi.org/10.1111/j.1467-8535.2005.00482.x

Corbin, S., \& Strauss, A. (2008). Basics of qualitative research: Techniques and procedures for developing grounded theory, (3rd ed., ). Thousand Oaks, CA: Sage.

Crampton, A. \& Ragusa, A.T. (2012). Communication and education: Finding the balance with 24/7 opportunities for students. International Journal of Technology, Knowledge and Society, Volume 8, Issue 1, pp.33-42. http://www.olt.gov.au/system/ files/resources/SD13_2708_Crampton_Report_2015.pdf

Crampton, A \& Ragusa, A.T. (2015). Exploring the role of technology in fostering sense of belonging in students studying by distance. Final report to Office of Learning and Teaching. www.olt.gov.au/system/files/resources/SD13_ 2708_Crampton_Report_2015.pdf.

Creswell, J. W. (2014). Research design: Qualitative, quantitative and mixed methods approaches, (4th ed., ). Thousand Oaks, CA: Sage.

Croxton, R. A. (2014). The role of interactivity in student satisfaction and persistence in online learning. MERLOT Journal of Online Learning and Teaching, 10(2), 35-50 https://doi.org/10.1016/j.iheduc.2013.10.001.

Desai, M. S., Hart, J., \& Richards, T. C. (2008). E-learning: Paradigm shift in education. Education, 129(2), $327-334$ http:// www.sciepub.com/reference/123507.

Dixson, M. D., Greenwell, M. R., Rogers-Stacy, C., Weister, T., \& Lauer (2017). Nonverbal immediacy behaviors and online student engagement: Bringing past instructional research into present virtual classroom. Communication Education, 66(1), 37-53 https://doi.org/10.1080/03634523.2016.1209222.

Eom, S. B., Wen, J. H., \& Ashill, N. (2006). The determinants of students' perceived learning outcomes and satisfaction in university online education: An empirical investigation. Decision Sciences Journal of Innovation Education, 4(2), 215-235 https://doi.org/10.1111/j.1540-4609.2006.00114.x.

García-Jiménez, L. (2012). Elements for a social theory of technologically mediated communication: From modernity to postmodernity. Estudios sobr e el Mensaje Periodístico, 18(1), 101-114 https://doi.org/10.5209/rev ESMP.2012.v18.n1.39357.

Garfinkel, H. (1967). Studies in ethnomethodology. Englewood Cliffs, NJ: Prentice-Hall.

Giddens, A. (1991). Modernity and self-identity: Self and society in the late modern age. Stanford: Stanford University Press.

Glaser, B. G., \& Strauss, A. L. (1967). The discovery of grounded theory: Strategies for qualitative research. New York: Aldine.

Goffman, E. (1967). Interaction ritual: Essays on face-to-face behavior. New York: Doubleday Anchor.

Gosper, M., Malfroy, J., \& McKenzie, J. (2013). Students' experiences and expectations of technologies: An Australian study designed to inform planning and development decisions. Australasian Journal of Educational Technology, 29(2), 268-282 https://doi.org/10.14742/ajet.127.

Gregory, M. S., \& Lodge, J. M. (2015). Academic workload: The silent barrier to the implementation of technologyenhanced learning strategies in higher education. Distance Education, 36(2), 210-230 https://doi.org/10.1080/ 01587919.2015 .1055056

Grossman, A. M., \& Johnson, L. R. (2016). Employer perceptions of online accounting degrees. Issues in Accounting Education, 31(1), 91-109.

Hardy, K. P., \& Bower, B. L. (2004). Instructional and worklife issues for distance learning faculty. In B. L. Bower, \& K. P. Hardy (Eds.), From distance education to e-learning:Lessons along the way. San Francisco: Jossey-Bass.

Hartnett, M., St. George, A., \& Dron, J. (2011). Examining motivation in online distance learning environments: Complex, multifaceted and situational. The International Review of Research in Open and Distance Learning,12(6), 20-37. http://dx.doi.org/10.19173/irrodl.v12i6.1030

Hendarman, A. F., \& Tjakraatmadja, J. H. (2012). Relationship among soft skills, hard skills and innovativeness of knowledge workers in the knowledge economy era. Procedia - Social and Behavioral Sciences, 52, 35-44 https://doi. org/10.1016/j.sbspro.2012.09.439.

Jaggars, S. S., \& Xu, D. (2010). Online learning in the Virginia community college system (CCRCWorking paper). New York, NY: Columbia University, Teachers College, Community College Research Center.

Jaggers, S. S. (2014). Choosing between online and face-to-face courses. The American Journal of Distance Education, 28(1), 27-38. http://dx.doi.org/10.1080/08923647.2014.867697.

Jurgenson, N. (2012). When atoms meet bits: Social media, the mobile web and augmented revolution. Futurelnternet, 4(1), 83-91 https://doi.org/10.3390/fi4010083.

Kemp, D., \& Norton, A. (2014). Review of the demand driven system: Final report. Australian Government: Department of Education and Training. 
Lee, J. (2010). Online support service quality, online learning acceptance, and student satisfaction. Internet and Higher Education, 13, 277-283 https://doi.org/10.1016/j.iheduc.2010.08.002.

Marshall, C., \& Rossman, G. (1999). Designing qualitative research, (3rd ed., ). Thousand Oaks, California: Sage Publications.

Muilenburg, L. Y., \& Berge, Z. L. (2005). Student barriers to online learning: A factor analytic study. Distance Education, 26(1), 29-48 https://doi.org/10.1080/01587910500081269.

Nagarajan, S., \& Edwards, J. (2014). Is the graduate attribute approach sufficient to develop work ready graduates. Journal of Teaching and Learning for Graduate Employability, 5(1), 12-28 https://doi.org/10.21153/jtlge2014vol5nolart565.

Neuman, W. L. (2011). Social research methods, (7th ed., ). Boston, MS: Pearson Education.

Norton, A., \& Cakitaki, B. (2016) Mapping Australian higher education 2016, Grattan Institute. https://grattan.edu.au/wp.../ 08/875-Mapping-Australian-Higher-Education-2016.p.

Norton, A. \& Cherastidtham, I. (2014). Mapping Australian higher education, 2014-15. Grattan Institute.

O'Neil, D. K., \& Sai, T. H. (2014). Why not? Examining college students' reasons for avoiding an online course. Higher Education, 68(1), 1-14 https://doi.org/10.1007/s10734-013-9663-3.

Otter, R. R., Seipel, S., Graeff, T., Alexander, B., Boraiko, C., Gray, J., Petersen, K., \& Sadler, K. (2013). Comparing student and faculty perceptions of online and traditional courses. Internet and Higher Education, 19, 27-35 https://doi.org/10. 1016/j.iheduc.2013.08.001.

Przybylski, A. K., Murayama, K., DeHaan, C. R., \& Gladwell, V. (2013). Motivational, emotional, and behavioral correlates of fear of missing out. Computers in Human Behavior, 29(4), 1841-1848 https://doi.org/10.1016/j.chb.2013.02.014.

Ragusa, A.T. (2007). The impact of socio-cultural factors in multi-cultural virtual communication environments: A case example from an Australian university's provision of distance education in the global classroom. In St-Amant, K. (Ed.) Linguistic and Cultural Online Communication Issues in the Global Age (Chapter 18, pp. 306-27), Idea Group Inc.

Ragusa, A.T. (2009). Peer learning and social interactions in an asynchronous learning environment. Handbook of Research on Social Interaction Technologies and Collaboration Software: Concepts and Trends, 2 Volumes. (Chap. 17, Section II). T. Dumova \& R. Fiordo (Eds.), Hershey: Information Science Reference.

Ragusa, A. T. (2010). Communication and social interactions in a technologically-mediated world. In A. Ragusa (Ed.), Interaction in Communication Technologies \& Virtual Learning Environments: Human Factors (chapter 1), (pp. 1-8). PA: Information Science Reference.

Ragusa, A. T. (2012). Writing for the social sciences. NSW: Pearson Education.

Rettie, R. (2009). Mobile phone communication: Extending Goffman to mediated interaction. Sociology, 43(3), 421-438 https://doi.org/10.1177/0038038509103197.

Richardson, J. C. (2017). Social presence in relation to students' satisfaction and learning in the online environment: A meta-analysis. Computers in Human Behaviour, 71, 402-417 https://doi.org/10.1016/j.chb.2017.02.001.

Shea, P. A., \& Bidjerano, T. (2014). Does online learning impede degree completion? A national study of community college students. Computers \& Education, 75, 103-111 https://doi.org/10.1016/j.compedu.2014.02.009.

Small, F., Dowell, D., \& Simmons, P. (2012). Teacher communication preferred over peer interaction. Journal of International Education in Business, 5(2), 114-128. https://doi.org/10.1108/18363261211281735.

Smith, M. C., \& Winking-Diaz, A. (2004). Increasing students' interactivity in an online course. Journal of Interactive Online Learning, 3(3), 1-25 http://www.ncolr.org/issues/jiol/v2/n3/increasingstudents-interactivity-in-an-online-course. Accessed Apr 2017

Standlee, A. (2016). Technology and making-meaning in college relationships: understanding hyperconnection. Qualitative Sociology Review, 12(2), 6-21. (http://www.qualitativesociologyreview.org/ENG/archive_eng.php)

$\mathrm{Xu}, \mathrm{D} .$, \& Jaggars, S. S. (2011). Online and hybrid course enrollment and performance in Washington state community and technical colleges (CCRC working paper no. 31). New York, NY: Columbia University, Teachers College, Community College Research Center.

Zembylas, M. (2008). Adult learners' emotions in online learning. Distance Education, 29(1), 71-87. http://dx.doi.org/10. 1080/01587910802004852

\section{Submit your manuscript to a SpringerOpen ${ }^{\circ}$ journal and benefit from:}

- Convenient online submission

- Rigorous peer review

Open access: articles freely available online

High visibility within the field

- Retaining the copyright to your article

Submit your next manuscript at $\boldsymbol{s p r i n g e r o p e n . c o m ~}$ 